\title{
PUBLICATION BIAS IN EPIDEMIOLOGICAL STUDIES SHORT COMMUNICATION
}

\author{
Nazish Siddiqi \\ Department of Epidemiology, Michigan State University, East Lansing, Michigan, USA
}

\begin{abstract}
SUMMARY
Communication of research findings is the utmost responsibility of all scientists. Publication bias occurs if scientific studies with negative or null results fail to get published. This can happen due to bias in submitting, reviewing, accepting, publishing or aggregating scientific literature that fails to show positive results on a particular topic.

Publication bias can make scientific literature unrepresentative of the actual research studies. This can give the reader a false impression about the beneficial effects of a particular treatment or intervention and can influence clinical decision making. Publication bias is more common than it is actually considered to be, but there are ways to detect and prevent it. This paper comments on the occurrence, types and consequences of publication bias and the strategies employed to detect and control it.
\end{abstract}

Key words: bias, publication bias, epidemiological studies, funnel plot, trim and fill method

Address for correspondence: N. Siddiqi, 2128 Fisher trail, Atlanta, GA 30345 USA. E-mail: nazish.siddiqi@gmail.com

Bias is difficult to avoid in research studies. A carefully designed study is likely to be relatively free of bias, but its elimination cannot be guaranteed. Moreover, too much effort to control bias at times, can compromise the usefulness and (reduce the) generalizability of the study.

Bias has been defined as 'Any systematic error in the design, conduct or analysis of a study that results in a mistaken estimate of an exposure's effect on the risk of disease' (1). Biases in scientific research can be broadly classified as either selection bias or information bias (2). They can occur anywhere in the course of the study from the selection of the study subjects to the final reporting of the results.

Publication Bias, a type of information bias, is defined as 'The tendency on the parts of investigators, reviewers and editors to submit or accept manuscripts for publication based on the direction or strength of the study findings' (3). Elaborating on that, Constantine remarks in her book, that research with statistically significant positive results is more readily submitted to journals for publication and is not only more likely to be published, but is published relatively quickly when compared to research with negative or null results (4). Publication bias is more common than it is usually considered to be. It is estimated that as much as $50 \%$ of the literature about a particular topic remains unpublished. Moreover, null studies are more than twice as likely to remain unpublished than studies with statistically significant results (5).

The objectives of this paper are to discuss the types and causes of publication bias, assess its consequences and examine/analyze ways to prevent or control it.

\section{Types and Causes of Publication Bias:}

Selective publication of studies with positive or statistically significant findings is the most commonly understood form of publication bias. This also leads indirectly to the file drawer problem which is the reluctance on part of researchers to submit manuscripts for publication that either show no effect or negative results (Table 1). There have also been claims that authors' name, prestige, institution, research topic and 'new versus conventional treatment' are factors that can favor publication of a study (6).

A recent study concluded that commercially funded and United States (US) based research is more likely to be published than non-commercially funded and non US based research. The authors considered two hundred and nine manuscripts submitted to the journal for publication from all over the world. Although, in this study the reviewers were blinded to the funding source and the country of origin, yet they still favored studies conducted in the US that were commercially funded and multicenter, over the ones that were foreign, non-funded and single center. This could be explained by the fact that authors' writing style and certain other study characteristics cannot be easily blinded (Table 1). Interestingly, in this investigation positive study outcome was not associated with a higher likelihood of publication. (7).

Publication bias can also occur if there are multiple publications of same study results or within study selective reporting of outcome, exposures or subgroup analyses. In these instances, it is very difficult to ascertain the magnitude of the bias (4).

\section{What Does Publication Bias Lead to?}

Introduction of bias in a research study can lead to misinterpretation of its results and may eventually lead to imprecise conclusions. Publication bias can result in misleading conclusions about the benefits of a particular treatment or intervention, or in other words, can give the impression of unfounded precision of results (2). This is due to the fact that readers get to witness just one side of the mirror; the other (negative results) side remains 
Table 1. Publication Bias (PB) operating at different levels

\begin{tabular}{|l|l|}
\hline Researchers by not submitting studies & $\begin{array}{l}\text { Also known as 'file drawer problem' is defined as reluctance on part of the investigators to submit for publica- } \\
\text { tion, studies with negative or no effect(4). }\end{array}$ \\
\hline Journal editors by favoring positive studies & $\begin{array}{l}\text { Although they strongly deny, yet they have at times been accused of favoring studies with positive results for } \\
\text { publication. There also is evidence that commercially funded, United States (US) based and multi center stud- } \\
\text { ies are more likely to be published than non-funded, foreign based or single center studies }(7,8) .\end{array}$ \\
\hline Reviewers by favoring positive studies & $\begin{array}{l}\text { They may pay more attention to the main results or the take home message as opposed to the scientific merit } \\
\text { of the investigation and consequently, at times very well designed and well conducted studies may not get } \\
\text { published if they report null or negative results }(6,8) .\end{array}$ \\
\hline Mass media & Media selectively publicizes new research with positive findings (9). \\
\hline Reference bias & $\begin{array}{l}\text { Studies reporting positive findings are cited more frequently in reviews than those reporting negative results } \\
(10) .\end{array}$ \\
\hline Secondary literature and meta-analyses & $\begin{array}{l}\text { A study conducted to investigate publication bias in secondary literature reported preferential translation of } \\
\text { studies from medline (primary literature) to ACP Journal Club (ACPJC) (secondary lit) based on positivity of } \\
\text { outcome (11, 12). }\end{array}$ \\
\hline
\end{tabular}

unseen. Publication bias in secondary literature like the previously mentioned example of ACPJC (Table 1) can misguide clinical practitioners in favoring certain treatments, because of overrepresentation of studies with positive outcomes (5).

Eyding and colleagues conducted a systematic review of published and unpublished literature comparing the benefits and harms of anti-depressant Reboxetine with either a placebo or selective serotonin reuptake inhibitors (SSRIs) in the acute treatment of depression. Contrary to what published literature indicated, they reported that Reboxetine is ineffective and in some cases harmful as an antidepressant. Publication bias distorted the available literature thereby favoring the treatment. This example highlights the urgent need for mandatory publication of clinical trials data (13).

\section{How Can Publication Bias Be Detected?}

Certain scientific methods can be employed for detecting publication bias. The simplest method is the examination of a 'funnel plot' and the use of the 'trim and fill method' to adjust for bias (Fig. 1) (6). A funnel plot is a plot of the effect size of each trial against some measure of its size, like precision, sample size or standard error $(4,6)$. These plots should be shaped like a funnel if there is no publication bias. This is due to the fact, that trials

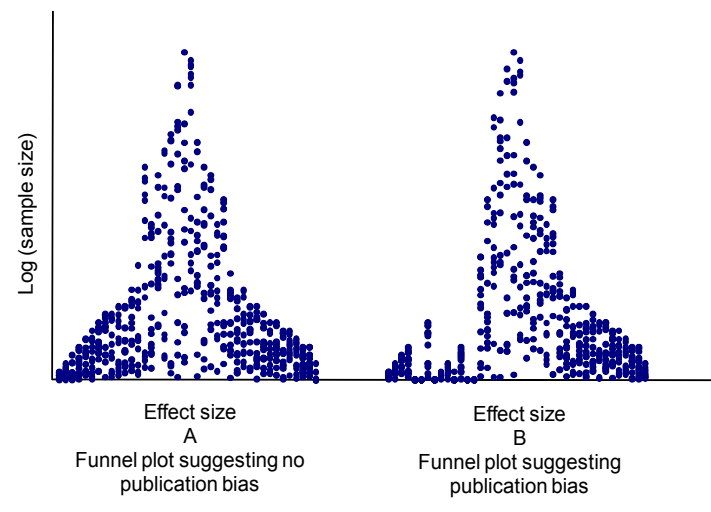

Fig. 1. The funnel plot. with smaller sample size have larger variation in the estimates of their effect size as compared to the ones with larger sample sizes $(6,12)$. The studies at the lower left end and the center of the funnel can be a victim of publication bias (Fig. 1 b). To adjust for this, the trim and fill method is used by first estimating the number of asymmetric trials on the right side of the funnel. These are the trials that do not have a left sided counterpart. These trials are then 'trimmed' from the plot leaving a symmetric remainder. Later meta-analytic procedures are used to estimate the center of the funnel. Finally the trimmed trials are replaced along with their missing mirror image counterparts, which are imputed or 'filled'. This method has helped in devising a test for the presence of publication bias by estimating the number of missing trials $(6,12)$.

\section{How Can Publication Bias Be Avoided/Prevented?}

Various strategies have been proposed to reduce and possibly eliminate selective publication of research studies.

\section{A Section for Null Results:}

This strategy has been adopted by the journal of Cancer Epidemiology, Biomarkers and Prevention. The journal has introduced a new section titled 'Null results in brief'. The main aim of this section is to promote scientists to report studies that were well conducted, but failed to reach statistical significance or show a positive result (14).

\section{Establishing an International Registry for Clinical Trials:}

Several authors have suggested that all clinical trials should be registered with an international registry right at their inception so as to avoid publication bias in the future on the basis of their results $(9,10)$. International Clinical Trials Registry Platform (ICTRP) recommends that all clinical trials be registered, with their objectives and endpoints clearly stated. This universal registration can help prevent data suppression by pharmaceutical agencies, institutions etc. by making the trials known to the public (15-17).

\section{On-line Journal Publications:}

Online journals are a relatively recent phenomenon. Since they are published online, there is less competition for space and the topic need not be very newsworthy (18). One such journal is 'The Journal of Negative Results in Biomedicine' which is an online bio-med central journal that encourages scientists to submit 
studies that fail to show statistical significance, challenge current dogmas or tenets, are controversial or are negative (19).

\section{Does Publication Bias Qualify as Scientific Miscon- duct?}

As scientists, it is our ultimate responsibility to report or make public our study results. In any research study, the study participants have invested their time and at times other valuables in the process. Therefore, it is our moral and ethical obligation to report what we concluded from the whole exercise. In his editorial in 'Cancer epidemiology biomarkers and prevention' Peter G. Shields sheds light on the hazards of not communicating research findings. He claims that obtaining comprehensive information about latest research is even more vital in the field of cancer epidemiology, as clinicians make vital decisions regarding treatment protocols for cancer patients (14).

Publication bias is a serious problem that should be minimized as much as possible. Scientists should eliminate it as much as possible by trying to publish their research findings irrespective of the direction of results. Editors and reviewers of journals should pay more attention to design, methods and conduct of the research studies to reach their editorial decisions rather than the final results of that particular study.

Although publication bias may not essentially qualify as scientific misconduct, it distorts science in a manner that can hinder progress in clinical as well as other types of scientific research. If scientific literature is composed of a biased sample of research studies it cannot provide unbiased conclusions.

\section{REFERENCES}

1. Schlesselman JJ, Stolley PD. Case-control studies: design, conduct, analysis. New York: Oxford University Press; 1982.

2. Gordis L. Epidemiology. 3rd ed. Philadelphia: Elsevier/Saunders; 2004.

3. Dickersin K. The existence of publication bias and risk factors for its occurrence. JAMA. 1990 Mar 9;263(10):1385-9.
4. Constantine NA. Publication bias. In: Boslaugh S, editor. Encyclopedia of epidemiology. Vol.1. Thousand Oaks, CA: Sage Publishers; 2008. p. 853-4.

5. Scherer RW, Dickersin K, Langenberg P. Full publication of results initially presented in abstracts. A meta-analysis. JAMA. $1994 \mathrm{Jul}$ 13;272(2):158-62. Erratum in: JAMA. 1994 Nov 9;272(18):1410.

6. Moller AP, Jennions MD. Testing and adjusting for publication bias. Trends in Ecology \& Evolution. 2001 Oct;16(10):580-6.

7. Lynch JR, Cunningham MR, Warme WJ, Schaad DC, Wolf FM, Leopold SS. Commercially funded and United States-based research is more likely to be published; good-quality studies with negative outcomes are not. J Bone Joint Surg Am. 2007 May;89(5):1010-8.

8. Olson CM, Rennie D, Cook D, Dickersin K, Flanagin A, Hogan JW, et al. Publication bias in editorial decision making. JAMA. 2002 Jun 5;287(21):2825-8.

9. Campion EW. Medical research and the news media. N Engl J Med. 2004 Dec 2;351(23):2436-7.

10. Gotzsche PC. Reference bias in reports of drug trials. Br Med J (Clin Res Ed). 1987 Sep 12;295(6599):654-6.

11. Carter AO, Griffin GH, Carter TP. A survey identified publication bias in the secondary literature. J Clin Epidemiol. 2006 Mar;59(3):241-5.

12. Sutton AJ, Duval SJ, Tweedie RL, Abrams KR, Jones DR. Empirical assessment of effect of publication bias on meta-analyses. BMJ. 2000 Jun 10;320(7249):1574-7.

13. Eyding D, Lelgemann M, Grouven U, Härter M, Kromp M, Kaiser T, et al. Reboxetine for acute treatment of major depression: systematic review and meta-analysis of published and unpublished placebo and selective serotonin reuptake inhibitor controlled trials. BMJ. 2010 Oct 12;341:c4737.

14. Shields PG. Publication bias is a scientific problem with adverse ethical outcomes: the case for a section for null results. Cancer Epidemiol Biomarkers Prev. 2000 Aug;9(8):771-2.

15. Simes RJ. Publication bias: the case for an international registry of clinical trials. J Clin Oncol. 1986 Oct;4(10):1529-41.

16. Abaid LN, Grimes DA, Schulz KF. Reducing publication bias through trial registration. Obstet Gynecol. 2007 Jun;109(6):1434-7.

17. World Health Organization. International Clinical Trials Registry Platform (ICTRP) [Internet]. Geneva: WHO [cited 2009 Aug 20]. Available from: http://www.who.int/ictrp/en/.

18. Song F, Eastwood A, Gilbody S, Duley L. The role of electronic journals in reducing publication bias. Med Inform Internet Med. 1999 JulSep;24(3):223-9.

19. Journal of Negative Results in Bio-medicine [Internet]. London: BioMed Central [cited 2009 Aug 20]. Available from: http://www.jnrbm.com/.

Received August 25, 2009 Accepted in revised form May 25, 2011 